\title{
The Design and Need for Jigs and Fixtures in Manufacturing
}

\section{Charles Chikwendu Okpala, Ezeanyim Okechukwu C.}

Department of Industrial/Production Engineering, Nnamdi Azikiwe University, Awka, Anambra State, Nigeria

Email address:

ockcharles@yahoo.com (C. C. Okpala),cc.okpala@unizik.edu.ng (C. C. Okpala)

To cite this article:

Charles Chikwendu Okpala, Ezeanyim Okechukwu C.. The Design and Need for Jigs and Fixtures in Manufacturing. Science Research. Vol. 3, No. 4, 2015, pp. 213-219. doi: 10.11648/j.sr.20150304.19

\begin{abstract}
The paper gave a detailed definition of jigs and fixtures, and also identified the numerous advantages that are associated with the use of jigs and fixtures in manufacturing to include: production increase, cost reduction, interchangeability and high accuracy of parts, reduction of the need for inspection and quality control expenses, reduction of accident as safety is improved, automation of machine tool to an appreciable extent, easy machining of complex and heavy components, as well as low variability in dimension which leads to consistent quality of manufactured products. The work also explained that since the design is dependent on numerous factors which are analyzed to achieve an optimum output, that jigs and fixtures should be made of rigid light materials to facilitate easy handling. For adequate strength and rigidity, a mild steel with 16 millimeters diameter was chosen for the design of a sample jig and fixture. Mild steel which contain about $0.29 \%$ of carbon are very cheap, and because of their easy availability are often the choicest material for the making of jigs of fixtures. With 1.5 as the material factor ' $\mathrm{k}$ ' for mild steel, a feed rate of 0.17 millimeter per revolution, and a drill diameter of 16 millimeters, the Thrust/Drilling force was calculated as $3094.2 \mathrm{~N}$. The Force acting on each of the lips was calculated as $1700 \mathrm{~N}$, the Torque (M) was gotten as $1360 \mathrm{~N}-\mathrm{mm}$, while the value of the Clamping Force was also calculated as $4080 \mathrm{~N}$. The calculated values confirmed that a 16 millimeter diameter mild will lead to the construction of a rigid and strong jigs and fixtures that will guarantee high machining accuracy, consistent quality of products, and interchangeability. Finall, the paper advocated that jigs and fixtures must be provided with adequate clearance which should allow for variations in size of components especially during forging, milling, and casting operations.
\end{abstract}

Keywords: Components, Work-Holding, Manufacturing, Production, Operation, Devices, Machining, Work-Piece, Clamping, Bushes

\section{Introduction}

The people's quest for manufactured goods has been growing rapidly over the years. Therefore, to meet up with the high demand, manufacturers have reacted by introducing innovative ways of manufacturing high quality products at a faster rate.The production processes has witnessed numerous changes and evolution with the introduction of numerous innovative manufacturing concepts which include Lean Production System, Cellular Manufacturing, Single Minute Exchange of Dies, as well as Takt Time Analysis. These creative approaches have necessitated the need for a reliable and cheaper tools and work-holding devices.

As the efficient running of a manufacturing company which demands a prompt and simple work positioning strategy for correct operations depends largely on the interchangeability of machine components and work-pieces, to ensure un-complication of assembly, and unit cost reduction, as well as to become competitive, reduce the enormous manufacturing cost, and also increase their profitability, the industry has resorted to streamlining its supply chain in a bid to maintaining a very low amount of inventory. This has also led to the demand for a better and cost effective work-holding devices which will ensure better quality products, reduce lead time, and also increase throughput.

Also, although some machining operations are so straightforward, like in turning where the job is secured tightly on the chuck while the turning operations are easily performed, some jobsin other operations may not be easily held on either the three or four jaw chucks, and may also require the tools to be guided by the means of a different device. This explains the need for production standard work-holding devices to 
increase the rate of manufacturing.

Jig is the device which guides the tool, while fixture is a device that securely holds the job in position during machining operations.

\section{Jigs and Fixtures}

Jigs and fixtures are manufacturing tools that are employed to produce interchangeable and identical components. They are unique tool-guiding and work-holding devices designed specifically for machining and assembling large number of parts. Chennu (2014), listed the following as the purposes of jigs and fixtures reduction of production cost, increase of production rate, high accuracy of products without any manufacturing defects, provision of interchangeability, easy machining of complex shaped parts, reduction of quality control costs, etc.

Jigs and fixtures eliminate the need for a special set up for every work-piece thereby facilitating production and also ensuring that every work piece is manufactured within a predetermined tolerance.

According to Meduettaxila (2012), Jigs and fixtures "eliminate the necessity of a special set up for each individual part." heobserved that once a jig or fixture is appropriately set up, that any number of duplicate componentscan be readily produced without additional set up

Also Mechnol (2015), observed that The main advantages of Jigs and fixtures are "durability, setup reduction, improvement in productivity, reduced decision making in operation selected from the standard components."

The major difference between a jig and a fixture is that jigs guide the cutting tool to its precise position, as well as locating and supporting the work-piece during operations.

The essential features of jigs and featuresinclude:

- Clamps position;

- Neatness of work-piece;

- Standardization;

- Idle time reduction;

- Set up time reduction;

- Hardened surfaces.

The application of jigs and fixtures in manufacturing operations lead to the production of faster, more accurate, and reliable products at a reduced cost.

\subsection{Jig}

A jig is a work-holding device that supports, holds, locates a work-piece and also guides the cutting tool for the desired machining operations. Its main objective is to ensure high degree of precision, interchangeability, and duplication in products'manufacturing, it is also applied to manipulate the location and movement of other tools.

Nanthakumar and Prabakaran (2014), explained that a jig is a type of custom-made tool used for the location and motion of another tool. They observed that the primary purpose of a jig is to provide repeatability, accuracy, and interchangeability in the manufacturing of products. Although the most common jigs are the drilling and boring jigs, they are all identical except for the shape, type, and the position of the bushings for drilling or boring.

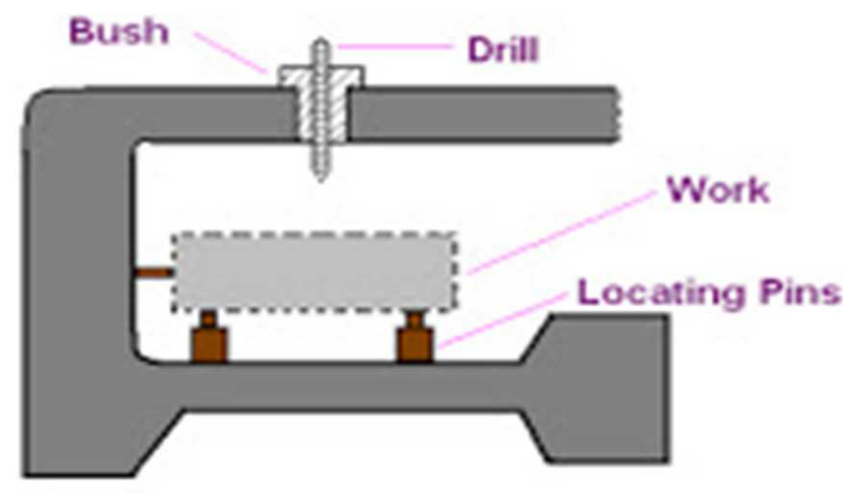

\section{-: Jig :-}

Figure 1. A typical Jig. Source: engineeringhut.blogspot.com/2010/11/jigsand-fixtures. html.

According to Joshi (2010), Jigs are imparted with tool guiding elements such as drill bushes, which regulate the tool to the right position in the work piece. He observed that they are rarely clamped on the machine table as it is essential to push the jig on the table to align the numerous bushes in the jig with the spindle of the machine. Thedifferent types of jigs are template jig, drilling jig, open type jig, etc.

\subsection{Fixtures}

Fixtures are rigid and sturdy mechanical devices which allow fast and precision machining with reliable quality, interchangeability, and lead time reduction. As a workholding device, fixtures do not position, guide, and locate the cutting tool, as it is achieved by making necessary adjustments on the machine.

Kaija, andHeino (2006), explained that the "main purpose of a fixture is to locate and in some cases hold a work-piece during either a machining operation or some other industrial processes." He pointed out that what makes fixtures unique is that they are all manufactured to fit a particular shape or part.

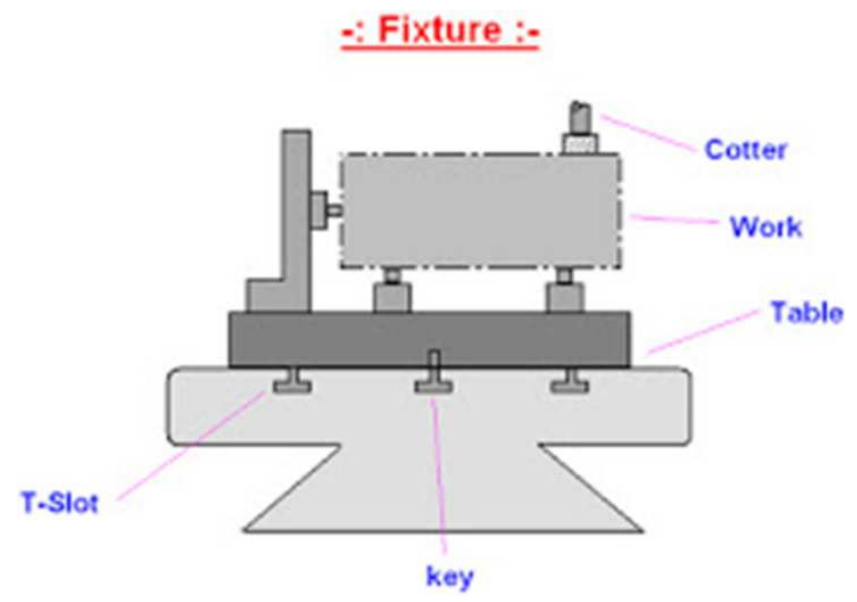

Figure 2. A typical fixture: Source: engineeringhut.blogspot.com/2010/11/jigs-and-fixtures.html. 
Fixtures often fastened to the machine table, are made to hold the work piece firmly and in the desired position during machining operations. Joshi (2010), stated that there are sometimes an arrangement in the fixture for adjusting the tool with respect to the work-piece/fixture, although the tool is not guided like in a jig.

While fixtures are always identified by the machine tool where they are applied, they have broader applications than jigs, and also manufactured for operations where the cutting tools cannot be easily maneuvered like the drilling or boring tools. The different types of fixtures are welding fixture, tapping fixture, milling fixture, boring and drilling fixture, milling fixture, turning fixture, etc.

\subsection{Advantages of Jigs and Fixtures}

The advantages of jigs and fixtures includebut not limited to the following:

- Production increase;

- Low variability in dimension, thereby leading to consistent quality of manufactured products;

- Cost reduction;

- Ensures interchangeability and high accuracy of parts;

- Reduces the need for inspection and quality control expenses;

- Reduces accident, as safety is improved;

- Semi-skilled machine operators can easily use them thereby saving the cost of manpower;

- The machine tool can be automated to an appreciable extent;

- Complex and heavy components can be easily machined;

- Easy assembly operations savelabour, and also lead to reduction of defective products;

- They eliminate the need for measuring, marking out, punching, positioning, alignments, and setting up for each work-piece thereby reducing the cycle and set up time;

- Increases technological capacities of machine tools;

- The application of more than one tool simultaneously on a work-piece can be achieved;

- Setting of higher values of some operating conditions like depth of cut, speed, and rate of feed can be attained because of the increased clamping capability of jigs and fixtures.

\subsection{Elements of Jigs and Fixtures}

The body, Clamping devices, Locating devices, and Tool guide/bushes are the major elements of jigs and fixtures.

\subsubsection{The Body}

As the most outstanding element of jigs and fixtures, the body is constructed by welding of different slabs and metals usually mild steel or by casting of cast iron. After the fabrication, it is often heat-treated for stress reduction as its main objective is to accommodate and support the job.

The different types of jig bodies are as follows:

Channel body type - this is fabricated from the regular steel channel.

Box body type - usually made very light, the box type jig body is adopted where a work-piece needs drilling in various parts, hence the jig is fabricated to have a required amount of drill bush plates.

Plane body type - this is the most common type of jig body and is often applied when the work-piece requires drilling or boring, hence the provision of drill bushes on it.

Leaf body type - usually made from block of steel as it holds and supports heavy components.

Built-up body type - this is made from standard steel.

\subsubsection{Clamping Devices}

Without sacrificing efficiency and effectiveness, the clamping devices must be very simple and easy to operate. Apart from holding the work-piece securelyin place, the strong point of clamping devices is its ability to withhold the strain of the cutting tool during operations. The bench vice is a popular example of a clamping device. The need for clamping the work-piece on the jig or fixture is to apply pressure and press it against the locating components, thereby fastening it in the right position for the cutting tools. The familiar clamping devices include:

Clamping screws - they are used for not too rigid clamping.

Hook bolt clamp - a simple clamping device generally used where the normal clamping tip cannot fit in.

Latch clamp - this is a unique clamp which provides space for the loading and the unloading of a work-piece through its latch or lid.

Other clamping devices are the $\mathrm{C}$ - clamp, the Bridge clamp, and the Heel clamp,

\subsubsection{Locating Devices}

Made with hardened steel and with different designs, the pin is the most popular device applied for the location of work-piece in jigs and fixtures.The pin's shank is press-fitted or driven into a jig or fixture. The locating width of the pin is made bigger than the shank to stop it from being pressed into the jig or fixture body because of the weight of the cutting tools or work-piece.

The pins are classified as follows:

Locating pins - the locating pins are used for the location of the work-piece when completed or reamed holes have been provided on the work-piece. The two types of locating pins are cylinderical and conical locating pins.

Jack pins - jackpins also referred to as spring pins are used for the location of work-piece whose dimension will vary during operation. The pin is designed to rise under spring pressure or in the contrary the weight of the work-piece pushes it down. As the position of the work-piece is firmly fixed, the locking screw is used to fasten the pin in the desired position.

Support Locating/Rest pins - these pins which ensure reliable and secure location are made to be either curved or flat. Those with flat heads are often used to provide support and location to machine surface, as more contact area is accessible during location. Because of their stability, the head 
support locating pins are for supporting coarse or rough surfaces during machining.

\subsubsection{Jig Bushing or Tool Guide}

Guiding parts like jig bushings and templates which must be wear resistant, interchangeable, and precise, are used to locate the cutting tool relative to the component being machined. Jig bushes are applied in drilling and boring, here for the drill to pass through, a bush fits into the hole of the jig.

Bushes are mainly made of reliable grade of tool steel in order to ensure hardening at a low temperature and also reduce the risk of fire cracking. Although, hardened steel bushes are preferred for guiding reamers, drills, and taps, the guiding tool bushings can also be made of cast iron.

The jig bushings are categorized into three: the linear wearing bushes, press-fit wearing bushes, and renewable wearing bushes.

\section{Selection of Materials}

There are a wide range of materials from where jigs and fixtures could be made, to resist tear and wear, the materials are often tempered and hardened. Also, phosphor bronze and other non-ferrous metals, as well as composites, and nylons for wear reduction of the mating parts, and damage prevention to the manufacturing part is also used. Some of the materials are discussed below:

- Phosphor Bronze: phosphor bronze is used in the production of jigs and fixtures for processes that involve making of interchangeable nuts in clamping systems like vices, and also inoperated feedings that require screws. As the manufacturing of screws is very expensive and also wastes a lot of time, the reduction of their tear and wear is often achieved by using replaceable bronze mating nuts made with phosphor bronze.

- Die Steels: the three variants of die steel - high chromium (12\%), high carbon (1.5 to $2.3 \%$ ), and cold working steels are applied in the production of jigs and fixtures for the making of thread forming rolls, as well as cutting of press tools. When alloyed with vanadium and molybdenum for it to retain toughness at very high temperature, die steels are applied in the fabrication of jigs and fixtures that are used in high temperature work processes which include extrusion, forging, and casting processes.

- High Speed Steels: high speed steels which contain more quantity of tungsten and less quantity of chromium and vanadium has high toughness, hardenability, hardness retention at high temperature, and good wear, tear and impact resistance. When tempered, they are applied in the production of jigs and fixtures for reaming, drilling, boring, and cutting operations.

- Carbon Steels: when tempered with oil, carbon steels are applied in the making of some jig and fixture parts which are exposed to tear and wear like the locators and jig bushes.

- Mild steels: mild steel which contain about $0.29 \%$ of carbon are very cheap and because of their easy availability are often the choicest material for the making of jigs of fixtures.

- Other materials for the making of jigs and fixtures include: Nylon and fiber, steel castings, stainless steel, cast iron, high tensile steels, case hardening steels, and spring steels.

\section{Design of Jigs and Fixtures}

The design of jigs and fixtures is dependent on numerous factors which are analyzed to achieve an optimum output. Jigs should be made of rigid light materials to facilitate easy handling, as it has to be rotated severally to enable holes to be drilled from different angles. It is recommended that four feet should be provided for jigs that are not bolted on the machine tool, to enable the jig to wobble if not well positioned on the table and thereby alert the operator. Drill jigs provide procedures for proper location of the work-piece with respect to the cutting tool, tightly clamp and rigidly support the work-piece during machining, and also guide the tool position and/or fasten the jig on the machine tool.

To achieve their expected objectives, jigs and fixtures consist of many elements:

Frame or body and base which has features for clamping;

The accuracy and availability of indexing systems or plates;

The extent of automation, capacity and type of the machine tool where jigs and fixtures will be employed;

Bushes and tool guiding frames for jigs;

The availability of locating devices in the machine for blank orientation, and suitable positioning;

Auxiliary elements;

The strength of the machine tool under consideration;

The precision level of the expected product;

Fastening parts;

The available safety mechanisms in the machine tool; The study of the fluctuation level of themachine tool.

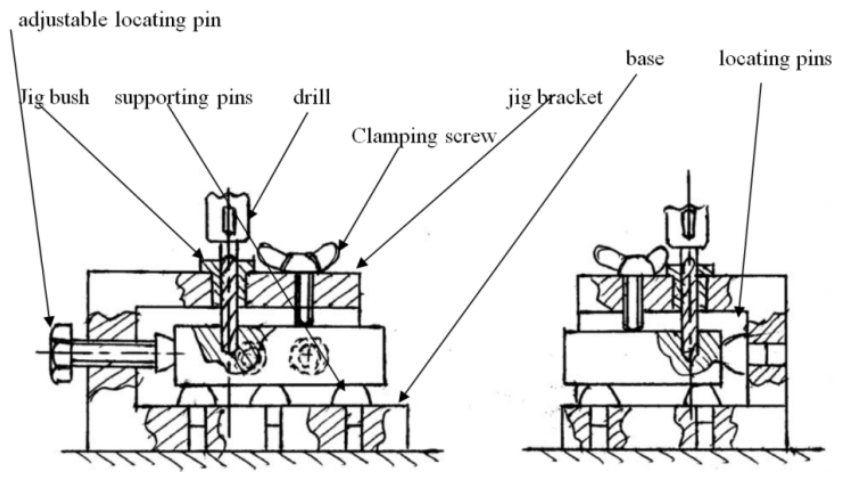

Figure 3. Major elements of jigs and fixtures.

The factors below are to be reflected upon during design, production, and assembly of jigs and fixtures due to the targeted increase in throughput, quality of products, 
interchangeability, and more accuracy.

- Guiding of tools for slim cutting tools like drills;

- Type of operations;

- Inspection requirements;

- Provision of reliable, rigid, and robust reinforcement to the blank;

- Production of jigs and fixtures with minimum number of parts;

- Fast and accurate location of the jig or fixture blank;

- Rapid mounting and un-mounting of the work-piece from the jig or fixture;

- Set up time reduction;

- Standard and quality parts must be used;

- Reduction of lead time;

- Easy disposal of chips;

- Enhanced flexibility.

Spogel (2014),advised that the design of jigs and fixtures must be fool-proof so that the tools, bushes, and components cannot be inserted except in the correct way. Apart from ensuring that locating points are made adjustable when the component is a rough casting and may be out of alignment, he admonished that the clamps should be located in the best position in order to resist the cutting tool pressure when at work.

A proper design must also incorporate tolerances at the design stage for jig andfixtures components that are standardized.

\section{Calculations}

The standard formulae for the various forces associated with the operations of jigs and fixtures are explained below:

$$
\text { Torque, } M=K * A * f * 0.8 * d * 1.8
$$

Thrust, $T=2 * K * B * f * 0.8 * d * 0.8+K * E * d * 2$

Where $\mathrm{d}$ is the diameter of the drill.

$\mathrm{A}, \mathrm{B}, \mathrm{E}$, and $\mathrm{K}$ are constants.

Also, Thrust/Drilling force $=1.16 * k * d(100 * s)^{0.85}$

Where $\mathrm{k}=$ material factor

$\mathrm{s}=$ feed in $\mathrm{mm} / \mathrm{rev}$

$\mathrm{d}=$ the diameter of the drill in millimeter $(\mathrm{mm})$

The Force acting on each of the lips

$$
P_{l}=\left(K_{l} * d * s\right) / 4
$$

The Torque, $\mathrm{M}$ is also calculated as

$$
\left(P_{l} * d\right) / 20
$$

The clamping Force $(\mathrm{Q})$ is given as

$$
\text { Torque }(M) * \text { safety factor }
$$

The constants for different work materials for the calculation of Torque (M) and Thrust $(\mathrm{T})$ are shown in the tables below:
Table 1. The work material constants for Torque and Thrust calculations. Source: Spogel (2014).

\begin{tabular}{ll}
\hline Work Material & K \\
\hline Steel,200Bhn & 24,000 \\
Steel, 300 Bhn & 31,000 \\
Steel, 400 Bhn & 34,000 \\
Most aluminum alloys & 7,000 \\
Most magnesium alloys & 4,000 \\
Most brasses & 14,000 \\
Leaded brasses & 7,000 \\
Cast iron, 165 Bhn mild steel, & 15,000 \\
Free-machining & 18,000 \\
resulfurized & 34,000 \\
Austenitic stainless steel (Type 316) & \\
\hline
\end{tabular}

Table 2. Torque and Thrust constants based upon ratios c/d or w/d. Source: Spogel (2014).

\begin{tabular}{lllll}
\hline c/d & $\begin{array}{l}\text { Approx. } \\
\text { w/d }\end{array}$ & $\begin{array}{l}\text { Torque } \\
\text { constant A }\end{array}$ & $\begin{array}{l}\text { Thrust } \\
\text { constant B }\end{array}$ & $\begin{array}{l}\text { Thrust } \\
\text { constant E }\end{array}$ \\
\hline 0.03 & 0.025 & 1.000 & 1.100 & 0.001 \\
0.05 & 0.045 & 1.005 & 1.140 & 0.003 \\
0.08 & 0.070 & 1.015 & 1.200 & 0.006 \\
0.10 & 0.085 & 1.020 & 1.235 & 0.010 \\
0.13 & 0.110 & 1.040 & 1.270 & 0.017 \\
0.15 & 0.130 & 1.080 & 1.310 & 0.022 \\
0.18 & 0.155 & 1.085 & 1.355 & 0.030 \\
0.20 & 0.175 & 1.105 & 1.380 & 0.040 \\
0.25 & 0.220 & 1.155 & 1.445 & 0.065 \\
0.30 & 0.260 & 1.125 & 1.500 & 0.090 \\
0.35 & 0.300 & 1.310 & 1.575 & 0.120 \\
0.40 & 0.350 & 1.395 & 1.620 & 0.160 \\
\hline
\end{tabular}

$* c-$ chisel edge length $(\mathrm{mm})$

$d-$ drill diameter $(\mathrm{mm})$

$w$ - web thickness $(\mathrm{mm})$

Table 3. Torque and Thrust terms based upon feed. Source: Spogel (2014).

\begin{tabular}{cccc}
\hline Feed, f, ipr & $\boldsymbol{f}^{\mathbf{0 . 8}}$ & Feed, $\mathbf{f}, \mathbf{i p r}$ & $\boldsymbol{f}^{\mathbf{0 . 8}}$ \\
\hline 0.0005 & 0.0025 & 0.012 & 0.030 \\
0.001 & 0.004 & 0.015 & 0.035 \\
0.002 & 0.007 & 0.020 & 0.045 \\
0.003 & 0.010 & 0.025 & 0.055 \\
0.004 & 0.012 & 0.030 & 0.060 \\
0.005 & 0.014 & 0.035 & 0.070 \\
0.006 & 0.017 & 0.040 & 0.075 \\
0.008 & 0.020 & 0.045 & 0.090 \\
0.010 & 0.025 & & \\
\hline
\end{tabular}

For adequate strength and rigidity, a mild steel with 16 millimeters in diameter was chosen for the design of a sample jig and fixture.

From equation (3), the Thrust/Drilling force $=1.16 * k *$ $d(100 * s)^{0.85}$

But $\mathrm{k}$ is the material factor, and the $\mathrm{k}$ for mild steel $=1.5$

$\mathrm{d}$ is the diameter of drill $=16 \mathrm{~mm}$ (as indicated above)

$\mathrm{s}$ is the feed rate $=0.17 \mathrm{~mm} / \mathrm{rev}$

substituting,

Thrust/Drilling Force $=1.16 * 1.5 * 16 *(100 * 0.17)^{0.85}$

$=27.84 * 11.114=309.42 \mathrm{Kgf}$

Therefore, Thrust/Drilling Force $=3094.2 \mathrm{~N}$ 
From equation 4 , the Force acting on each of the lips $P_{l}$ is given as:

$$
P_{l}=\left(K_{l} * d * s\right) / 4
$$

Recall that $K_{l}$ for mild steel $=250 \mathrm{~kg} / \mathrm{mm}^{2}, \mathrm{~d}=16 \mathrm{~mm}$, and $\mathrm{s}=0.17 \mathrm{~mm} / \mathrm{rev}$

$$
\text { Substituting, } P_{l}=(250 * 16 * 0.17) / 4
$$

Therefore, the Force acting on each of the lips $P_{l}=170 \mathrm{Kgf}$ $=1700 \mathrm{~N}$

$$
\begin{aligned}
& \text { From equation 5, The Torque } \mathrm{M}=\left(P_{l} * d\right) / 20 \\
& \text { Substituting, Torque } \mathrm{M}=(1700 * 16) / 20 \\
& \text { Torque, } \mathrm{M}=1360 \mathrm{~N}-\mathrm{mm}
\end{aligned}
$$

From equation 6, the clamping Force (Q) is given as Torque $(M) *$ safety factor

With a safety factor of 3 , we have:

Clamping Force $(\mathrm{Q})=1360 * 3=4080 \mathrm{~N}$

The Design Principles for Jigs and Fixtures

To ensure that the jigs and fixtures as production tools and work-holding devices are able to produce interchangeable and duplicate parts with high degree of precision, efforts are made at the design stage to incorporate important features that will ensure that quality components are assembled and machined properly.

According to Pachbhai and Raut (2014), the design of Jigs and fixtures depend on the following factors: workpiece and finished component size and geometry study, the machine size and capacity, the machine's extent of automation, availability of clamping arrangement and locating devices in the machine, the accuracy of the avaiable indexing devices, the machine tools rigidity, the neededaccuracy level in the quality of work to be produced, etc.

Apart from fabricating jigs and fixtures that are very rigid in order to protect the preset machine accuracy, it should also be error-proof thereby preventing wrongly loaded components from sitting properly inside jigs and fixtures. To enhance the attainment of Single Minute Exchange of Dies (SMED) as pioneered by Shingeo Shingo, jigs and fixtures must be provided with adequate clearance which should allow for variations in size of components especially during forging, milling, and casting.

To ensure the safety of the workmen using the jigs and fixtures, bolts and nuts should not protrude on the body but be placed inside them; also sharp corners that could lead to cuts should be smoothened.

\section{Conclusion}

Jigs and fixtures are manufacturing tools that are employed to produce interchangeable and identical components. They are unique tool-guiding and work-holding devices designed specifically for machining and assembling large number of parts. They eliminate the need for a special set-up for every work-piece thereby facilitating production and also ensuring that every work piece is manufactured within a predetermined tolerance.The design of jigs and fixtures is dependent on the operation type as well as the machine tool to be used for the operation. They are fabricated with heat-treated steel that are corrosion and wear resistant.

There are numerous advantages that are associated with the use of jigs and fixtures, they include: production increase, low variability in dimension thereby leading to consistent quality of manufactured products, manufacturing cost reduction, interchangeability and high accuracy of parts, reduces the need for inspection and quality control expenses, reduces accident as safety is improved, semi-skilled machine operators can easily use them thereby saving the cost of manpower.

Other benefits are: the machine tool can be automated to an appreciable extent, complex and heavy components can be easily machined, easy assembly operations save labour, reduction of defective products, elimination of the need for measuring, marking out, punching, positioning, alignments, and setting up for each work-piece thereby reducing the cycle and set up time, increase technological capacities of machine tools, setting of higher values of some operating conditions like depth of cut, speed, and rate of feed can be attained because of the increased clamping capability of jigs and fixtures.

The paper explained that since the design of jigs and fixtures is dependent on numerous factors which are analyzed to achieve an optimum output that they should be made of rigid light materials to facilitate easy handling. For adequate strength and rigidity, mild steel with 16 millimeters in diameter was chosen for the design of a sample jig and fixture. Mild steel which contain about $0.29 \%$ of carbon are very cheap, and because of their easy availability are often the choicest material for the making of jigs of fixtures.

With 1.5 as the material factor ' $k$ ' for mild steel, a feed rate of 0.17 millimeter per revolution, and a drill diameter of 16 millimeters, the Thrust/Drilling force was calculated as 3094.2 N, the Force acting on each of the lips was calculated as $1700 \mathrm{~N}$, the Torque $(\mathrm{M})$ was gotten as $1360 \mathrm{~N}-\mathrm{mm}$, while the value of the Clamping Force was also calculated as $4080 \mathrm{~N}$. The calculated values confirmed that a 16 millimeter diameter mild will lead to the construction of a rigid and strong jigs and fixtures that will guarantee high machining accuracy, consistent quality of products, and interchangeability.

\section{References}

[1] Joshi, P. (2010). "Jigs and Fixtures" Tata McGraw Hill Education, New Delhi, India.

[2] Nanthakumar, K. and Prabakaran, V. (2014). "Design and Fabrication Testing of Combined Multipurpose Jig and Fixture" IOSR Journal of Mechanical and Civil Engineering. www.iosrjournals.org.

[3] Lin, Q., Burdick, J., and Rimon, E. (2006). "Constructing Minimum Deflection Arrangements Using Invariant Norms" IEEE Transactions on Automation Science and Engineering, Vol. 3, No. 3. 
[4] Blogspot (2010). "Introduction to Jigs and Fixtures" [Online] engineeringhut.blogspot.com/2010/11/jigs-andfixtures.html[Accessed 5 May 2015].

[5] Spogel (2014). "Mini project on Jigs and Fixtures" [Online] http://files.spogel.com/miniprojectsin-mech/p-0027--Jigs-andFixtures.pdf[Accessed 18 May 2015].

[6] Kaija, T. and Heino, P. (2006). "The Optimization of Onwafer Shield-Based Test Fixture Layout" IEEE Transactions on Microwave Theory and Techniques, Vol. 54, No. 5.

[7] Meduettaxila (2012). "Jigs and Fixtures Module" [Online] https://2k9meduettaxila.files.wordpress.com/2012/04/scanjigs-and-fixtures.pdf [Accessed 22 May 2015].
[8] Mechnol (2015). "Applications of Jigs and Fixtures" [Online] http://www.mechnol.com/applications-of-jigs-andfixtures.html [Accessed 11 July 2015].

[9] Pachbhai, S. and Raut, L. (2014). “A Review on Design of Fixtures" International Journal of Engineering Research and General Science, Vol. 2, Issue 2.

[10] Chennu, V. (2014) "Jigs and Fixtures and their Purposes" [Online] http://www.memechanicalengineering.com/2015/02/jigs-and-fixtures.html [Accessed 12 July 2015]. 